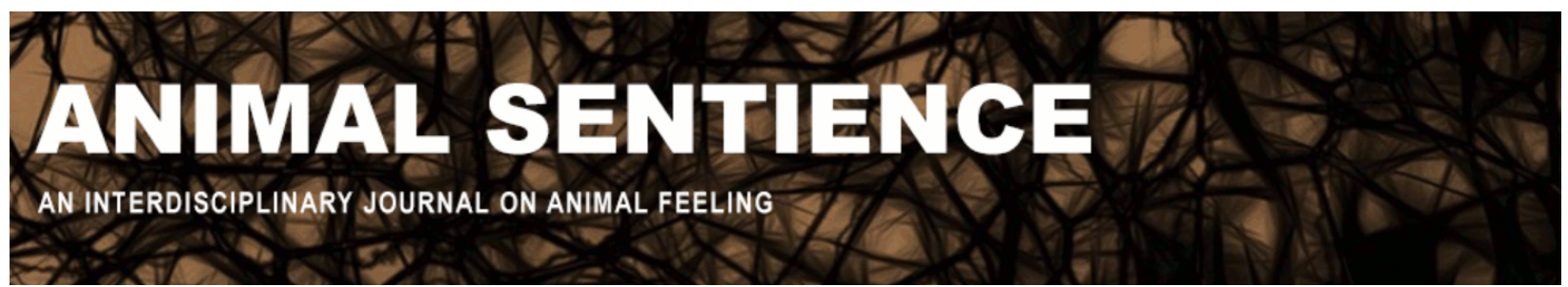

Spiegel, Rainer (2019) Protecting patients who lack a voice. Animal Sentience 27(11)

DOI: $10.51291 / 2377-7478.1541$

Date of submission: 2020-01-09

Date of acceptance: 2020-01-10

(c)

This article has appeared in the journal Animal

Sentience, a peer-reviewed journal on animal

cognition and feeling. It has been made open access,

free for all, by WellBeing International and deposited

in the WBI Studies Repository. For more information,

please contact

wbisr-info@wellbeingintl.org.

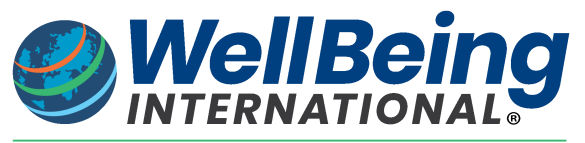

SOLUTIONS FOR PEOPLE, ANIMALS AND ENVIRONMENT 


\title{
Protecting patients who lack a voice
}

Commentary on Treves et al. on Just Preservation

\author{
Rainer Spiegel \\ Department of Anesthesiology, Intensive Care and Pain Management \\ BG Trauma Center, University of Tübingen
}

\begin{abstract}
Neither human young today nor future human generations nor non-human species have a voice in protecting the biosphere. Treves et al. propose courts and trustees for defending their interests. I describe an analogy with attempts to represent the interests of children and comatose patients in medicine.
\end{abstract}

\footnotetext{
Rainer Spiegel is a specialist in internal medicine with additional training in emergency medicine, anesthesiology and intensive care medicine. He has experienced many situations where a patient was in a coma, thus unable to speak, and the challenge was to find out what was in the patient's best interest. Website
}

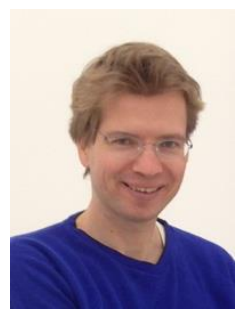

Treves et al. (2019) argue that we currently fail to protect the biosphere. In the conflict of interest with current adult generations, they propose that the needs of young and future human generations as well as those of nonhuman species should be represented in court. I fully agree; from my daily work in medicine, I know that both younger and older children can be very mature in gaining an understanding of their diseases and in discussing different treatment alternatives with their parents and physicians. Young human generations should indeed have a voice in decision-making processes. Alexander (2019) too calls for greater inclusiveness in protecting the biosphere, citing the gender and ethnic inequity in the scientific community; Bergstrom (2019) argues for the empowerment of women in rural societies. It is likewise imperative to ensure a representation of nonhuman organisms (e.g., Gray, 2019), who have no voice and cannot be asked to decide - not only animals, but plants (Attfield, 2019). The ecosystem itself needs to be protected for future generations (e.g., Palmer \& Fischer, 2019). All these questions need careful further consideration.

Courts and trustees. Along with commentators Baker (2019), Gray (2019) and Gupta (2019), I appreciate Treves et al.'s (2019) proposal to have trustees (and courts) to defend interests. A few words of caution, however, as we cannot always rely on courts in decision-making. Courts take time; and ecological as well as mortal interests cannot always afford to wait. As scientific evidence is frequently interpreted differently, there is the potential for conflicts between stakeholders (Gray, 2019; Gupta, 2019). Trustees need to be experts not only concerning the scientific evidence, but also concerning ecological ethics (Washington, 2019). If a court has taken a decision 
and contrary scientific evidence subsequently emerges, it could take a long time for the court to revise its decision; biological time constants might be shorter, and more urgent.

Court decisions and comatose patients. Many of my patients on the intensive care unit (ICU) are comatose. As part of the ICU team involving nurses, respiratory therapists, physiotherapists, psychologists, hospital chaplaincy, social workers and physicians from different specialties, we always try to act in the patients' best interests. If a patient is in a coma and no advance directives have been made, it can be challenging to determine what their best interests are; the patient cannot speak. This can become an issue when different treatment alternatives exist, each with advantages and disadvantages, but a delay in decision-making would almost certainly be associated with disadvantages. So we have meetings with the patients' loved ones and relatives. When doubts remain, court decisions can help, but they can take much longer. If a patient has not named a trustee, the court will appoint a trustee to act in the patient's best interests (e.g., the patient's partner or an independent conservator). But it can take time to appoint a trustee, whereas the patient's condition might not allow further delay in treatment decisions. Under these conditions, the ICU team decides and carries out the emergency treatments it judges necessary.

In protecting the biosphere, there might likewise arise situations where emergency decisions need to be made when there is no time to wait for court decisions (e.g., in natural disasters). In such cases, it would be desirable that experts who are able to define an emergency and can be trusted to apply ecological ethics (e.g., Washington, 2019) be empowered to act quickly. What disasters will happen in the future is obviously unknown, but if trustees for specific areas of expertise are selected in advance, they can react quickly when a disaster strikes. A case in point would be the tragedy currently unfolding in Australia.

\section{References}

Alexander, S. M. (2019). Reconciling just preservation. Animal Sentience 27(6).

Attfield, R. (2019). Futurity, selves and further organisms. Animal Sentience 27(4).

Baker, L. (2019). To preserve or to conserve. Animal Sentience 27(7).

Bergstrom, B. J. (2019). Just reductionism: In defense of holistic conservation. Animal Sentience 27(8).

Gray, J. (2019). Granting political representation to non-humans. Animal Sentience 27(5).

Gupta, R. (2019). Just preservation: From vision to reality. Animal Sentience 27(9).

Palmer, C., \& Fischer, B. (2019). Just policy paralysis? Animal Sentience 27(3).

Treves, A., Santiago-Ávila, F. J., \& Lynn, W. S. (2019). Just preservation. Animal Sentience 27(1). Washington, H. (2019). Justice for nature. Animal Sentience 27(2). 


\section{PhD Scholarship in Foundations of Animal Sentience (ASENT) London School of Economics}

The Foundations of Animal Sentience project (ASENT), a five-year ERC-funded project led by Dr. Jonathan Birch, aims to study the methodological foundations of animal sentience research and the link between sentience and animal welfare. The project seeks to recruit one PhD student. The student will contribute to the project either by exploring the methodological foundations of animal sentience research, or by investigating the pathway from animal sentience research to consequences for animal welfare legislation and policy and/or animal ethics.

The student, at the time of starting the $\mathrm{PhD}$, should have an excellent undergraduate degree and a completed Masters degree in philosophy or another relevant subject, such as comparative psychology, cognitive science, or animal welfare science. The primary supervisor of the $\mathrm{PhD}$ project will be Dr. Jonathan Birch. If you have any questions or want to know more about the project, please write to Jonathan at j.birch2@Ise.ac.uk.

The successful applicant will receive full funding for a 4-year PhD at the LSE, including full payment of tuition fees AND a maintenance stipend of $\mathbf{\$ 1 8 , 0 0 0}$ per annum. To apply, please apply to the MPhil/PhD in Philosophy at the LSE in the usual way, carefully following all the requirements described on the LSE's website: http://www.lse.ac.uk/study-atlse/Graduate/Degree-programmes-2020/MPhilPhD-Philosophy. When you apply, please indicate clearly in your application (in both your Statement of Academic Purpose AND your Research Proposal) that you wish to be considered for the ASENT scholarship.

You should include, in your research proposal, a substantial description (of at least 1,500 words) of a research project relevant to ASENT. You MAY, if you wish, include TWO research proposals in the same document: a proposal relevant to ASENT, and a proposal on a different subject that you would pursue if awarded an LSE Studentship or a LAHP (AHRC) scholarship. If you do this, please indicate clearly which of the two proposals is relevant to ASENT.

\section{CLOSING DATE: 24 JANUARY 2020.}

It is expected that interviews will be conducted in late January or in February. 